\title{
Research and Application of Project-Based Learning in Modern Control Theory Course
}

\author{
Yizhou Mao, Shaoqiang Yuan \\ School of Automation Science and Electrical Engineering \\ Beihang University \\ Beijing, China \\ ysq1960@sina.com
}

\begin{abstract}
Project-Based Learning (PBL) is a new teaching method which is characterized by projects and students as main part, widely used in theory teaching and practice teaching. This paper analyzed advantages, methods, principles and problems of PBL. We have conducted in-depth research on PBL theory and put it into teaching practice in modern control theory course. Inverted Pendulum System as the project are discussed, aiming at the teaching modes reform of modern control courses. Through our practice we conclude PBL play an important role in encouraging collaborative and cooperative learning among students. At last, some problems of PB L are pointed out for more attention.
\end{abstract}

Keywords-PBL; project design; modern control; Inverted Pendulum System

\section{INTRODUCTION}

Project-Based Learning (PBL) is a teaching method in which students gain knowledge and skills by working for an extended period of time to investigate and respond to an authentic, engaging and complex program or project [1]. It originated in Europe's education thought. The first prototypes are the 18th century European engineering education and the 19th century American cooperation. The theory of PBL tends to be perfect after the 20th century and becomes an important theoretical trends of thought. PBL is established on the basis of constructivism theory. Constructivists believe that the world is objective existence, but the understanding of the world and the meaning is each person to decide. In the study of the constructivism, the function of learning objective just like a lighthouse plays a whole guidance function. In the dynamic process of the study, we should encourage learners to establish their own goal and assess the progress in the process of reaching the target through different ways to achieve goals.

Traditional teaching method focuses on teachers, neglects students in cognition role. Especially, most Chinese students are accustomed to teacher-centered passive education. It is not good for the cultivation of students' creative abilities and thought. By comparison, The advantages of PBL are as follows:

1) Set clear, reasonable and realistic goals in learning. In pursuing goals, these goals lead and improve students' abilities to analyze and solve problems with professional knowledge.

2) Help students to play the main roles. In the past, most students learn for examination and the students become the "pocket" of teachers teaching knowledge. While project based learning teaching method lets students' accepting knowledge from passive state to positive state, which provides a creative and democratic learning environment, autonomous learning becomes a new learning style [2].

3) Cultivate students' ability of analyzing and solving problems. PBL is a process of using the new knowledge or skill to solve the problem one by one. Students can know about the subject deeply by investigation, analysis, cooperation, synthesize and practice. Also students can strengthen the ability of mastering their basic theory, analysis and solving problem [3].

4) Promote the graded teaching. In the teaching of PBL, different projects have different characters. And even for the same project, different teaching objects can also have a certain difference. For different types of students, students can select topic purposefully according to certain differences, which satisfy their different requirements respectively, make each student to obtain the good development.

\section{PROJECT DESIGN}

In the process of PBL, the design of teaching project is the key to the whole teaching, the quality of project has a direct influence on the teaching effect. PBL should include the basic teaching knowledge and the teaching goal, can also stimulate students' interest in learning and achieve a certain teaching effect. In the design of the project, according to the different course knowledge points, it is better to let a comprehensive project divide into several sub-projects which are independent and interrelated to each other. Then let the sub-project divided into several tasks. Each task can over certain course points, keys and difficulties. Then, every task sets up the relevant question. In the design of the project, we need to consider the following principles:

This research was financially supported by Graduate Education Development Foundation of Beihang University. (No.4003032) 
1) The design of project should have feasibility. Considering the reality of students, the design of the project had better more familiar, understandable, and interesting such as students' management system, automatic control systems and so on. The design of the project can neither too big nor too simple. So we can inspire students' interest in learning and guide students' studies in an independent way.

2) The design of the project should have comprehensive application. Combine the knowledge which is mastered and the knowledge which is about to study. Integrate the subject relevant contents. In this way, students blend the old with the new knowledge. Thus they improve the students' ability of comprehensive application and the ability of project development.

3) All kinds of projects should link up with each other in the content and the teaching requirement. The topic of project had better advanced, novel, practical. Curriculum system can form a complete set of training system through gradually enhanced [4].

\section{PBL IN MODERN CONTROL COURSE}

Modern control theory experiment is a professional technology course, initiates students into some control theories. In this paper, the project driven teaching method is adopted and the design principles of example projects are discussed, aiming at the teaching modes reform of the modern control courses. The whole process of PBL practice in modern control course can be divided into seven steps away.

\section{A. Project Design}

The name of project is "Inverted Pendulum System". Inverted pendulum system is recognized as the typical experimental equipment in modern control theory, is typical physical model in the control theory of teaching and scientific research [5]. It has been widely used at home and abroad as a typical experimental teaching system in modern control theory and computer control technology. We can set up different levels of the experiments of the computer control system for senior undergraduate and graduate students. We can conduct system modeling, system simulation, system design and some integrated, systematic, researching experiments. The method of design can be pole method, optimal control method, fuzzy control method, LQR control method and many kinds of intelligent control and modern control methods. The real object figure is shown as Fig. 1:

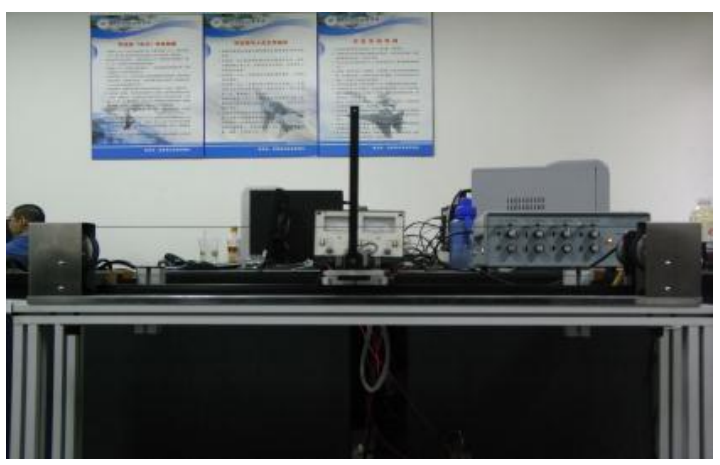

Fig. 1. Inverted Pendulum System

The reasons for the project design are as follows:

1) The subject has strong engineering background and moderate difficulty.

2) Physical experiment control is inspiring, practical and can attract students' interest.

3) Inverted Pendulum System is a teaching platform which concludes software design and hardware realization. The project can combine automatic control principle, computer control, modeling simulation, microcomputer principle with some other course about control. The circuit diagram is shown in Fig. 2:

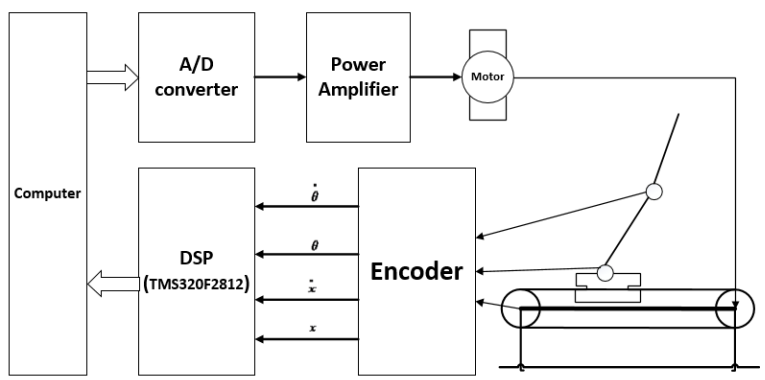

Fig. 2. The circuit diagram of Inverted Pendulum System 


\section{B. Requirement of Project}

The design requirement includes system technology index and the function of control software.

\section{1) System technology index}

a) The time for reaching stability of inverted pendulum is less than 3 seconds.

b) Inverted pendulum has certain anti-interference ability and keep in 5 minutes.

c) Axial movement of the inverted pendulum is less than $\pm 45 \mathrm{CM}$.

\section{2) Function of control software}

a) State feedback coefficient.

b) Real-time record and display the position of the inverted pendulum, the speed and angular of inverted pendulum (including curve and digital display).

c) The interface of software is friendly, including tips and help items (optional).

\section{Provision of Hardware}

High performance TMS320F2812 digital signal processor (DSP), Signal collection circuit based on photoelectric encoder, Motor control circuit based on the PWM. Students use existing resources of laboratory to accomplish projects. Teachers provide additional equipment according to demand of students.

\section{Determination of Control Scheme and Software}

Control scheme and control algorithm are put forward by the students, and are discussed together with the teachers. The software can be selected by students for completing real-time control task.

\section{E. Group Requirements}

The group is made of 3 or 4 students, in order to reflect the team cooperation spirit. Everyone in the team should be responsible for some part of the project, such as component testing, system debugging and so on.

\section{F. Standard of Evaluation}

The method for evaluation combines self assessment with teacher comments. And the rating criteria are as follows:

1) The amount of participation for the students and the work finished.

2) Parameters and curve of the system.

3) The function of the software and the effect of the interface.

4) The quality of the project reports.

5) The spirit of unity and cooperation.

\section{G. Process of Teaching}

Before the start of project design, we will broadcast the work designed by the students before and analyze the characteristic s of the early works, in order to inspire the students' thought. Based on this, the teacher will do the design counseling for two times. At the first time, the teacher will explain the design methods of the system. Next time, teacher will analyze and evaluate computer control design ideas. With the project going on, we will meet all kinds of problems from students. As students' study enthusiasm is very high, when they meet difficulties that stop them go on the project, teachers should instruct or explain. So teachers' workload increases significantly, and the requirement for the teacher's knowledge is very high. After determining the content of the project, we need to arrange the project schedule and finish within one month. During carrying on the project, the laboratory will open for the students. Students can come to do the experiment at any time and can discuss with teacher when having problems.

TABLE I. GUIDING PLAN OF TEACHING

\begin{tabular}{|c|l|}
\hline Week & \multicolumn{1}{c|}{ Study and design content (just for reference) } \\
\hline 1 & Task assignment and formulate project schemes \\
\hline 2 & Schemes evaluation and improvement \\
\hline 3 & Control algorithm design and improvement \\
\hline 4 & Computer control software design and improvement \\
\hline 5 & System with hardware and software debugging \\
\hline 6 & Inspection and evaluation \\
\hline
\end{tabular}




\section{EFFECT ANALYSIS OF PBL IN MODERN CONTROL COURSE}

Our educational experiment center has organized to teach and train a batch of students by using PBL in modern control course since 2015. Students cooperate to complete complex nonlinear model design, system design, real-time control program writing, system software and hardware debugging, etc. In the process of teaching, students' enthusiasm and the sense of responsibility obviously strengthened. Analysis, organization and coordination ability of students are improved significantly. Students further grasp the simple use of modern control theory, lay a foundation of graduation project and work of control after graduation. Fig. 3 shows different control algorithms renderings by two teams, which shows PBL in modern control course pushes different project ideas.
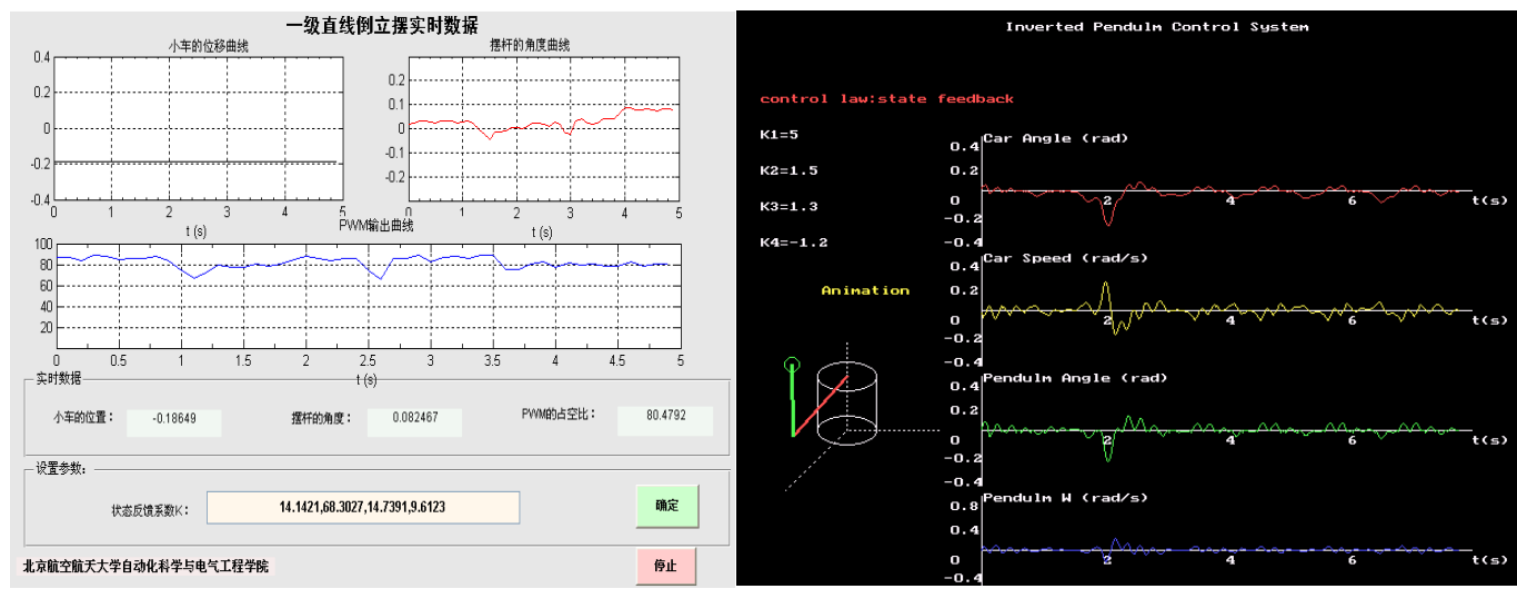

Fig. 3. LQR control and Fuzzy PID control rendering

The teaching effect of PBL is remarkable. At the same time, problems in the practice of PBL are also heeded.

\section{A. Select Suitable and Practical Project}

The selection of project should accord with current enterprise production practice. The design of project should be able to reflect the general nature of the similar things. Because of the open teaching equipment is less, most of the experimental equipment is designed according to the verification experiment. Sometimes, some plans proposed by students about hardware equipment are difficult to achieve. Therefore, it is necessary to build suitable experiment platform of the project about automatic control major.

\section{B. Self-improvement of Teachers}

Many teachers work for a long time in colleges and have higher theoretical level, but they are short of practical software development experience. Due to the use of modern technology, teachers are no longer the only source of information. So teachers should also update their knowledge and information, otherwise they cannot give students the right guidance.

\section{SUMMARY}

In conclusion, application of PBL in control system course is feasible and necessary. The traditional teaching method only focuses on the last results. While in the project based learning teaching method, the learning process is a process that everyone can participate in. PBL could not only link and consolidate students' knowledge of different disciplines, achieve the links and integration in interdisciplinary knowledge, but also facilitate to improve the abilities of students in literature search, independent thinking, self-learning, analyzing and solving problems, communication, coordination and teamwork. PBL presents a good way to cultivate the students' creative and practical capability. Practice of PBL in modern control theory shows that PBL has a good teaching effect and can be spread in engineering colleges.

\section{REFERENCES}

[1] E. Butun, H. C. Erkin, L. Altintas. A new teamwork-based PBL problem design for electrical and electronic engineering education:a system approach. International Journal of Electrical Engineering Education, Apr 2008.

[2] Zhihua Shen, Shaoqiang Yuan. Study and application of PBL in control system course[c]. 2012 7th International Conference on Computer Science \& Education (ICCSE 2012).2012.4 Page(s): 2874 -2877.

[3] Andreas Breiter, Görschwin Fey, Rolf Drechsler. Project-Based Learning in Student Teams in Computer Science Education[J]. Facta Universitatis Series : Electronics and Energetics. 2005(2)

[4] Nor Azliana Akmal Jamaludin, Shamsul Sahibuddin, Kamaruzaman Jusoff, Nur Hafizah Hidayat. Development of a Project-Based Learning Approach in Requirement Engineering[J]. International Journal of Computer Science and Information Security. 2010(9)

[5] Edgar Sanchez, Victor Flores. Real-time underactuated robot swing-up via fuzzy PI+PD control[J]. Journal of Intelligent \& Fuzzy Systems . 2006 (1) 